\title{
ENFERMEDAD DE PAGET EXTRAMAMARIA
}

\author{
(Extramammary Paget's disease)
}

Revista Médica Sinergia Vol.3 Num:7

Julio 2018 pp: 3 - 5

ISSN:2215-4523

EISSN:2215-5279

http://revistamedicasinergia.com

\author{
1 Dra. Kimberly Herrera Sánchez \\ ${ }^{1}$ Hospital de Guápiles, Limón, Costa Rica
}

DOI: https://doi.org/10.31434/rms.v3i8.131

\section{RESUMEN}

Es una neoplasia poco frecuente y de crecimiento lento que ocurre dentro del epitelio, es un adenocarcinoma poco común, que afecta la piel y las glándulas apocrinas abundantes. Está relacionado con otros tipos de cáncer. Es más frecuente en personas caucásicas entre 50 y 80 años. Al principio, los síntomas son inespecíficos, por lo tanto, el diagnóstico y el tratamiento generalmente se retrasan. Las lesiones típicas consisten en placas eritematosas o pardos, las lesiones se localizan principalmente en áreas ricas en glándulas apocrinas como genitales, perianal, ingles axiles, aunque puede ocurrir en cualquier parte de la piel o mucosas. La cirugía sigue siendo el tratamiento de elección. El pronóstico es generalmente bueno. la tasa de supervivencia a 5 años supera el $90 \%$.

PALABRAS CLAVES: Cancer, glándulas apocrinas, placas eritematosas, neoplasias malignas, carcinoma.

\section{ABSTRACT}

Is a rare and slow-growing malignancy which occurs within the epithelium, is a rare adenocarcinoma that affects the skin and abundant apocrine glands.It is related to other types of cancer. Is most prevalent in Caucasian people between 50 to 80 years.

At first the symptoms are non-specific, therefore, diagnosis and treatment are usually delayed. Typical lesions consist of erythematous or brown plaques, the lesions are located mainly in areas rich in apocrine glands such as genitals, perianal.

Surgery remains to be the preferred treatment of choice. Prognosis is generally good. the 5 -year survival rate exceeds $90 \%$.

KEY WORDS: Cancer, apocrine glands, erythematous plaques, malignant neoplasms, carcinoma.

\section{INTRODUCCIÓN}

La enfermedad de Paget extramamaria

es una forma muy rara de adenocarcinoma intraepitelial que afecta la piel con abundantes glándulas apocrinas. Puede acompañarse o no de otras neoplasias malignas dependiendo si es de tipo primario o secundario. 
Se relaciona con cáncer anexial subyacente en el 24 y $33 \%$ de los casos y con cáncer visceral en el 12 y $15 \%$ de los casos, principalmente gastrointestinales y de vías urinarias o en órganos con revestimiento continuo como perianal.

Se asocia a:

- Cáncer de mama

- Cáncer de cuello uterino

- Cáncer de recto

- Cáncer de ovarios

- Cáncer de uretra

- Cáncer de colón

- Cáncer de próstata

- Cáncer de vagina

- Cáncer de endometrio

- Cáncer de riñón

\section{EPIDEMIOLOGÍA}

La enfermedad de Paget extramamaria es una patología muy infrecuente con una incidencia aún desconocida. Se estima que no supera el $6,5 \%$ del conjunto de enfermedades de Paget y hay pocos casos descritos.

Generalmente afecta a individuos de raza blanca con edades entre los 50 y 80 años y es más frecuente en mujeres, aunque en la raza asiática afecta mayormente a los hombres. La incidencia real no se conoce.

\section{PATOGENIA}

Existen 2 teorías sobre su origen.

- La primera se refiere a una diferenciación anormal de las células epidérmicas de la capa basal del estrato germinativo en donde la enfermedad de Paget es una neoplasia independiente a una segunda neoplasia (Enfermedad de Paget primario).

- La segunda se refiere a una metástasis epidérmica de un carcinoma subyacente (enfermedad de Paget secundaria).

\section{CLÍNICA}

Al principio los síntomas son inespecíficos, por ello, generalmente se retrasa el diagnóstico y el tratamiento.

Las lesiones típicas consisten en placas eritematosas 0 pardo infiltradas generalmente con bordes únicos bien definidos a veces edematosas con exudados, prurito doloroso 0 incluso asintomático. La superficie puede estar rugosa con liquenificación, erosiones o costras. Es raro, pero puede encontrarse nódulos infiltrados, vegetaciones 0 linfadenopatías.

Las lesiones se localizan principalmente en zonas ricas en glándulas apocrinas como genitales, perianal, ingles, axilas aunque puede ocurrir en cualquier parte de la piel o mucosas.

El $65 \%$ se localiza en vulva, aunque representa solo el $2 \%$ de los carcinomas de este sitio. El $20 \%$ se localiza a nivel perianal y $14 \%$ en genitales masculinos. Raro encontrarlo en ingles o axilas. En el $65 \%$ de los casos la lesión permanece in situ.

\section{DIAGNÓSTICO}

No existe un protocolo establecido para el diagnóstico, el tratamiento y el seguimiento por ser una neoplasia rara. El diagnóstico se da principalmente por clínica e histología.

La biopsia mostrará células con citoplasma pálido y abundante, con 
núcleos grandes y pleomórfico, excéntricos y con forma de sello de anillo. Además, nucléolos prominentes. Debe realizarse el estadiaje de la enfermedad por medio de ultrasonografía abdominal y ginecológica, colonoscopia y mamografía.

\section{DIAGNÓSTICO DIFERENCIAL}

Dentro del diagnóstico diferencial:

- Lesiones eccematosas

- Liquen simple crónico

- Liquen escleroso

- Liquen atrófico

- Liquen plano

- Psoriasis invertida

- Intertrigo candidiasico

- Eritroplasia de Queyrat

- Enfermedad de Bowen

- Melanoma amelanocítico

- Pénfigo benigno familiar

\section{TRATAMIENTO}

El tratamiento de elección es la extirpación quirúrgica amplia con márgenes libres de lesión. Se puede utilizar también la cirugía micrográfica de Mohs que disminuye la tasa de recidivas.

Otras alternativas incluyen el láser de $\mathrm{CO} 2$, el imiquimod tópico, la radioterapia, crioterapia y terapia fotodinámica pero el riesgo de recidiva es muy alto llegando a ser del 50 a $60 \%$.

\section{PRONÓSTICO}

Debido al carácter multicentrico y los márgenes mal definidos hay recidiva del 16 y $44 \%$ de los casos, lo que disminuye del 8 a $28 \%$ si se utiliza la cirugía de Mohs.

La tasa de supervivencia a 5 años supera el $90 \%$ y en ocasiones existe regresión espontánea después de la resección quirúrgica parcial.

La supervivencia empeora en la enfermedad extramamaria de Paget con invasión dérmica 0 cuando existen neoplasias

asociadas.

\section{BIBLIOGRAFÍA}

1. Blasco G., Martín A., Garrido C., Tercedor J. (2015). Enfermedad extramamaria de Paget: 10 casos. Actas Dermo- Sifiliográficas, 106, e1-e5.

2. Monti F., Caruso A., Garay I., Kurpis M. . (2016, diciembre 12 ). Enfermedad de paget extratamaria: presentación de caso y revisión de la literatura. Colegio Iberoamericano de Dermatologia. , 45, 25-28.

3. Tapia O., Kam S. (agosto 2014). Enfermedad Extramamaria de Paget. Rev Chil Cir, 66, 371 374.

Recepción: 10 Abril de 2018

Aprobación: 20 Junio de 2018 